\section{The Rise of University Mergers in Europe}

\section{Thomas Estermann and Enora Bennetot Pruvot}

Thomas Estermann is director offunding, governance, and public policy development at the European University Association (EUA). E-mail: thomas.estermann@eua.be. Enora Bennetot Pruvot is program manager at the European University Association. E-mail: enora.pruvot@ eua.be. Note: A full report on university mergers is available on the EUA web site at: http://www.eua.be/Libraries/Publications_homepage_list/DEFINE_Thematic_Report_2_University_Mergers_in_Europe_final.sflb.ashx.

$\mathrm{M}$ ergers and concentration processes are not a recent phenomenon in the European higher education landscape. They constitute one of the responses to a series of change drivers - such as globalization, internationalization, the drive for quality, expectations surrounding new modes of teaching, rankings, the growing importance of research and innovation within the economic development agenda, and above all a challenging economic environment. The view that, by gaining mass, universities can generate economies of scale and rationalize the use of resources has been an important driver for merger and concentration processes. However, there is a lack of comprehensive evaluation whether at the system or at an institutional level. The European University Association (EUA) has recently conducted a study analyzing these processes in 25 European higher education systems from an efficiency angle, exploring the rationale for universities to merge, and assessing the efficiency dimension of these developments.

There is a wide spectrum of collaboration projects and initiatives in place between European universities, including various forms of cooperation, from research projects to strategic alliances. Mergers are complex processes, whereby new legal institutions are created or where several institutions are brought together under a common umbrella to form a tightly connected federation.

Between 2000 and 2015, around Ioo mergers have been recorded in 25 European higher education systems. There has been a continuous increase in numbers since 2000 from 3-5 mergers per year until 2006, between 7 and 8 mergers per year between 2007 and 2012, peaking in 2013 and 2014 with I2 and I4 mergers per year.

The increase from 2007 onwards is also due to a number of bigger systemwide reforms like the wave of mergers in Denmark in 2007; in Belgium in the French-speaking community over the period 2009-20II; and in Flanders in 20I3. Also, outstanding is the evolution in France, which combines a series of individual mergers to the broader trend of establishing "university communities" (federative type of cooperation entities) in 20I4 and 2015.

\section{Rationales and Aims}

There is a wide array of drivers for mergers and the rationale behind them typically includes academic factors (e.g., expected positive impact on research output and learning and teaching outcomes), organizational factors (e.g., redeployment of university structures), and financial factors (e.g., more efficient use of funding through economies of scale).

Increased quality in both research and teaching activities is a frequent aim of mergers and is derived from the pooling of academic talent and infrastructure, greater financial or staffing resources, and opportunities for interdisciplinary research with a wider variety of academic subject areas.

\section{The view that, by gaining mass, univer- sities can generate economies of scale and rationalize the use of resources- and has been an important driver for merger and concentration processes.}

In the case of systemwide reforms, the aim is often related to the need to consolidate the higher education landscape-to overcome fragmentation, achieve critical mass, avoid duplication of programs, create synergies (for instance by integrating universities and research centers), or adapt to changing demographic dynamics.

Universities also consider mergers as a means of strengthening their institutional position, both at home and on the international stage. Mergers are seen as an effective way to gain a greater profile and attract foreign staff and students, as well as to generate additional opportunities to undertake international collaboration.

\section{Economic Gains Should Not Be the Main Driver}

The achievement of economic gains, such as economizing financial and human resources, has been a strong expectation in many systems across Europe. Due to the basic characteristics of the funding system in many European countries, increasing staff and student numbers is seen as advantageous from a financial perspective. The potential to generate more revenues from private sources may also be a consideration. Likewise, there can be economies of scale in the provision of services-such as more efficient delivery of 
professional services and possibilities for streamlining arising from the enlarged infrastructural stock. However, experience shows that economic gain should not be the primary driver for undertaking a merger process, if only because of the high transition and implementation costs. There are often long-lead times, when it comes to the implementation of mergers. Even when the processes have been completed, the real financial and institutional effects of the transformation may take some years to become fully apparent. Institutions involved in mergers often acknowledge that they underestimated how long it would take to mainstream procedural change (e.g., human resources and finance processes) and establish cultural change. Underestimating the duration of the transition period leads to allocating too little time and resources to complete all the work as envisaged in the plan, which also has a knock-on effect on the delivery of efficiencies and the overall success of the merger.

\section{Elements for Successful Mergers}

University leaders and managers, involved in merger processes, thus need to focus on sound pre-evaluation and costing but also need to ensure good planning and implementation as well as productive relationships with public authorities. They must also promote an inspired vision and leadership, fostering both trust among and the involvement of staff and the wider community.

\section{Due to the basic characteristics of the funding system in many European countries, increasing staff and student numbers is seen as advantageous from a financial perspective.}

The merger should be chiefly supported by a strong academic and business case, considering that mergers are lengthy, resource-consuming processes that are difficult to reverse. It is important to specify defined assessment criteria and apply these equally across the whole institution, to arrive at a balanced and comparable assessment of the wider situation.

A merger process may not be the best option for the institutions concerned-once an evaluation of the costs involved (both real and opportunity costs) and the potential benefits (both academic and financial) have been carried out. The university leadership and relevant stakeholders should consider other possible cooperation options, in order to ensure that the most suitable way forward is selected. The overall goal should be the development of balanced structures and adequate processes that facilitate, rather than disrupt or hinder, the academic mission of the institution.

\section{Shifting Private-Public Pat- terns in Short-Cycle Higher Education Across Europe}

\section{Snejana Slantcheva-Durst}

Snejana Slantcheva-Durst is associate professor of Higher Education at the University of Toledo, United States. E-mail: Snejana.SlantchevaDurst@utoledo.edu. IHE regularly publishes articles on private higher education from PROPHE, the Program for Research on Private Higher Education, headquartered at the University of Albany.

Tnstitutions for advanced education of a nonuniversity 1 type-labeled tertiary short-cycle higher educationspread quickly throughout most of Europe in the ig6os and I970s, as a result of rising demand for higher education, growing diversification of the student body, and the changing needs for high-skilled manpower of industrialized societies. The institutional diversity in short-cycle provision was tremendous-including tertiary higher schools, technological institutes, colleges, academies, tertiary professional centers, higher professional schools, vocational schools, and many others. By the 2000 s, short-cycle programs served close to I8 percent of Europe's postsecondary students. Programs, focused primarily on professional training of short duration, of a terminal character, and opportunities for transfer to research universities, were limited to nonexistence. European short-cycle education developed both public and private sectors, with private initiatives often covering areas neglected by public universities, or in rising demand. By 2002, enrollments in the private short-cycle sector had grown to I, 246,480 , almost half of all students $(49 \%)$ in short-cycle programs across Europe.

\section{Changing Size and Shape of the Short-Cycle}

Prior to the 2003 Berlin Summit of the European ministers of higher education, short-cycle institutions and their programs were rarely considered an integral part of higher education systems. However, since 2003, and promoted by the Bologna process, a different and innovative kind of short-cycle higher education programs have been spreading throughout Europe. Unlike the predominantly terminal training short-cycle education programs of the past, the Bologna-driven short-cycle programs fulfill the dual role 